\title{
Expression of transport proteins in the rete mirabile of european silver and yellow eel
}

\author{
Gabriel Schneebauer ${ }^{1,2}$, Victoria Drechsel ${ }^{1,2}$, Ron Dirks $^{3}$, Klaus Faserl $^{4}$, Bettina Sarg ${ }^{4}$ and Bernd Pelster $r^{1,2,5^{*}}$
}

\begin{abstract}
Background: In physoclist fishes filling of the swimbladder requires acid secretion of gas gland cells to switch on the Root effect and subsequent countercurrent concentration of the initial gas partial pressure increase by back-diffusion of gas molecules in the rete mirabile. It is generally assumed that the rete mirabile functions as a passive exchanger, but a detailed analysis of lactate and water movements in the rete mirabile of the eel revealed that lactate is diffusing back in the rete. In the present study we therefore test the hypothesis that expression of transport proteins in rete capillaries allows for back-diffusion of ions and metabolites, which would support the countercurrent concentrating capacity of the rete mirabile. It is also assumed that in silver eels, the migratory stage of the eel, the expression of transport proteins would be enhanced.

Results: Analysis of the transcriptome and of the proteome of rete mirabile tissue of the European eel revealed the expression of a large number of membrane ion and metabolite transport proteins, including monocarboxylate and glucose transport proteins. In addition, ion channel proteins, $\mathrm{Ca}^{2+}$-ATPase, $\mathrm{Na}^{+} / \mathrm{K}^{+}$-ATPase and also $\mathrm{F}_{1} \mathrm{~F}_{0}$-ATP synthase were detected. In contrast to our expectation in silver eels the expression of these transport proteins was not elevated as compared to yellow eels. A remarkable number of enzymes degrading reactive oxygen species (ROS) was detected in rete capillaries.

Conclusions: Our results reveal the expression of a large number of transport proteins in rete capillaries, so that the back diffusion of ions and metabolites, in particular lactate, may significantly enhance the countercurrent concentrating ability of the rete. Metabolic pathways allowing for aerobic generation of ATP supporting secondary active transport mechanisms are established. Rete tissue appears to be equipped with a high ROS defense capacity, preventing damage of the tissue due to the high oxygen partial pressures generated in the countercurrent system.
\end{abstract}

\section{Background}

In physoclist fishes, i.e. in fish in which the embryonic connection of the swimbladder to the esophagus is lost during early development, the swimbladder is filled with gas molecules by diffusion from the blood and from swimbladder gas gland cells [1]. To generate the required high gas partial pressures to drive diffusion gas gland cells in the swimbladder epithelium secrete acid into the

\footnotetext{
*Correspondence: bernd.pelster@uibk.ac.at

${ }^{5}$ Institut für Zoologie Leopold-Franzens-Universität Innsbruck,

Technikerstr. 25, A-6020 Innsbruck, Austria

Full list of author information is available at the end of the article
}

blood, switching on the Root effect [2-6]. The resulting initial increase in oxygen partial pressure, the so called single concentrating effect [7], is then in a second step multiplied by countercurrent concentration in the rete mirabile of the swimbladder [6-9]. The rete has been considered to function by passive diffusion and hydraulic (osmotic) transport [10-12], although Steen [13] suggested that lactate may be transported from the venous to the arterial side in the rete mirabile of the European eel. A re-assessment of lactate and water movements in the rete by measurement of hemoglobin and of metabolite concentrations in blood samples collected anterior and posterior to the rete mirabile of the European 
eel revealed a significant back-diffusion of lactate from venous capillaries to the arterial side, but no significant osmotic gradient and no water movement was detected [14]. This would require presence of lactate transport proteins in the rete, i.e. presence of monocarboxylate carrier proteins [15]. Including the back-diffusion of solutes in the rete and the salting-out effect, i.e. the reduction of gas solubility with increasing solute concentration in blood [16], in model calculations revealed that the backdiffusion of solutes even enhances the countercurrent concentrating capacity of a rete [17]. The possible presence of transport proteins in rete mirabile membranes, indicated by the recorded lactate movements in the rete, therefore could significantly support the countercurrent concentrating ability of the rete and thus enhance the capacity of the rete to generate elevated gas partial pressures. This would imply that the rete mirabile is not just a passive exchanger, and the countercurrent concentrating ability of the rete could not only be modified by changing the surface area of the capillaries, but also by modifying the expression of transport proteins in rete capillaries.

In many fish, the arterial capillaries of the rete mirabile are in intimate contact with the gas gland cells and in close proximity to the venous capillaries of the rete mirabile $[18,19]$. Thus, collection of arterial and venous blood samples at the swimbladder side of the rete is difficult without contamination by the secretory activity of gas gland cells. In Anguillidae, such as the European eel, however, the two retia mirabilia of the swimbladder are bipolar and clearly separated from the gas gland cells. Therefore, blood samples can be collected at the arterial entrance and exit of the rete, and at the venous entrance and exit of the rete. For this reason, the eel has become a model species for the analysis of swimbladder physiology $[13,20,21]$. In the eel, each rete consists of about 30,000 to 40,000 arterial capillaries, which on the swimbladder pole of the retia give raise to two or three larger arterial vessels supplying the swimbladder epithelium, consisting of gas gland cells. From there the venous blood returns in two or three larger veins to the retia mirabilia, forming 20,000 to 30,000 venous capillaries, running parallel to the arterial capillaries with a diffusion distance of about $2 \mu \mathrm{m}[22,23]$.

The European eel is a catadromous fish spending most of its life cycle as so-called yellow eel in the European freshwater system. In preparation of the spawning migration eels pass the process of silvering to prepare for the transition to seawater. Silver eels then return to the spawning grounds in the Sargasso Sea, a journey taking about 5 to 6 months, perhaps even longer [24]. During silvering, which has been described as a secondary metamorphosis and puberty like event $[25,26]$, the size of the eel rete mirabile increases, indicating an improvement of the countercurrent concentrating ability [6,7]. For American eel a two- to three-fold increase in rete length has been reported, and in the Japanese eel a 1.6-fold increase has been detected $[27,28]$. Recent tracking studies revealed that migrating silver eels perform daily vertical migrations covering depth changes of several hundred meters $[24,29,30]$. The concomitant changes in hydrostatic pressure significantly affect the volume of the flexible-walled swimbladder, and it has been assumed that swimbladder function is improved during the process of silvering [24, 31]. Previous studies revealed significant changes in the transcriptome and the proteome of swimbladder gas gland cells associated with silvering, although the swimbladder is not involved in any osmoregulatory phenomenon. We therefore hypothesized that the countercurrent concentrating capacity of the rete mirabile, the second essential component of a physoclist swimbladder [1], would also be improved during silvering. We hypothesized that the countercurrent concentrating capacity of the rete mirabile would be supported by the expression of solute transport proteins in rete capillaries. Furthermore, during silvering the expression of these proteins would be enhanced, providing further support for the countercurrent concentration. To test these hypotheses, we analyzed and compared the transcriptome as well as the proteome of rete mirabile tissue of European yellow and silver eels. Our previous studies on gas gland cells could only be performed on separate tissue samples, so that a correlation between transcriptome and proteome could not be tested. We therefore aimed at obtaining both, transcriptome and proteome data from each individual fish, in order to connect transcriptome and proteome data.

\section{Results}

On average ( 5 yellow eels; 6 silver eels), a cDNA library was sequenced at a depth of $\sim 16$ mio raw reads. Alignment to the European eel reference genome [32] resulted in about $71 \%$ mapped gene reads and 32,674 transcripts that could be hit by at least one read in the transcriptome. Comparing the transcriptome of yellow and silver eels, 99 differentially expressed genes were detected at the level of $p<0.01,79$ of these genes could be assigned to a known function. Restricting this analysis to genes expressed with a relative expression value higher than 50 (base mean value) resulted in only 47 genes that were differentially transcribed, out of which 41 had a predicted function (Table 1). Therefore, the data sets were combined for further analysis to identify genes that are generally transcribed in rete endothelial cells of European yellow and silver eels.

Pathway analysis using the Reactome pathway browser revealed that in 25 pathways between $27 \%$ and $61 \%$ of the in the Reactome database listed genes were transcribed 
Table 1 Between yellow and silver eels differentially expressed genes detected in the transcriptome with a base mean value $>50$. ( $p$ $<0.01$ ). Using a more stringent $p$-adjust value none of these genes is significantly different

\begin{tabular}{|c|c|c|c|}
\hline Name & Description & baseMean & pval \\
\hline abcg2 & atp-binding cassette sub-family g member 2 & 55 & $5,38 \mathrm{E}-04$ \\
\hline $\operatorname{acc} 2 a$ & amiloride-sensitive cation channel 2- neuronal & 67 & $1,66 \mathrm{E}-05$ \\
\hline angl4 & angiopoietin-related protein 4 & 1302 & $8,71 \mathrm{E}-03$ \\
\hline $\operatorname{ats} 17$ & a disintegrin and metalloproteinase with thrombospondin motifs 17 & 493 & 2,38E-03 \\
\hline $\operatorname{axn2}$ & axin-2 & 50 & $3,78 \mathrm{E}-03$ \\
\hline$c 85 c b$ & coiled-coil domain-containing protein $85 c-b$ & 105 & $9,25 \mathrm{E}-03$ \\
\hline ceam5 & carcinoembryonic antigen-related cell adhesion molecule 5 & 144 & $6,96 \mathrm{E}-03$ \\
\hline cooal & collagen alpha-1 chain flags: precursor & 126 & $3,50 \mathrm{E}-03$ \\
\hline edil3 & egf-like repeat and discoidin i-like domain-containing protein 3 & 133 & $2,41 \mathrm{E}-03$ \\
\hline edn2 & endothelin-2 & 430 & $4,53 \mathrm{E}-03$ \\
\hline fras1 & extracellular matrix protein fras1 flags: precursor & 787 & $1,92 \mathrm{E}-06$ \\
\hline gbgt1 & globoside alpha- -n-acetylgalactosaminyltransferase 1 & 69 & $9,94 \mathrm{E}-03$ \\
\hline gpda & glycerol-3-phosphate dehydrogenase cytoplasmic & 356 & $5,16 \mathrm{E}-04$ \\
\hline gpda & glycerol-3-phosphate dehydrogenase cytoplasmic & 226 & $6,40 \mathrm{E}-03$ \\
\hline gtd2b & general transcription factor ii-i repeat domain-containing protein $2 b$ & 73 & $4,60 \mathrm{E}-03$ \\
\hline ha18 & h-2 class i histocompatibility q8 alpha chain flags: precursor & 63 & 7,96E-03 \\
\hline hebp2 & heme-binding protein 2 & 3544 & 1,17E-03 \\
\hline hrs/1 & hras-like suppressor & 534 & $9,16 \mathrm{E}-03$ \\
\hline hs3s1 & heparan sulfate glucosamine 3-o-sulfotransferase 1 & 558 & 2,87E-03 \\
\hline ic1 & plasma protease $\mathrm{c} 1$ inhibitor & 905 & $4,32 \mathrm{E}-03$ \\
\hline kalm & anosmin-1 & 129 & 4,77E-05 \\
\hline lgi1 & leucine-rich glioma-inactivated protein 1 flags: precursor & 160 & $9,80 \mathrm{E}-03$ \\
\hline lyg & lysozyme g & 192 & $6,21 \mathrm{E}-03$ \\
\hline mboa2 & membrane-bound o-acyltransferase domain-containing protein 2 & 56 & $6,91 \mathrm{E}-03$ \\
\hline mica2 & protein mical-2 & 65 & $7,23 \mathrm{E}-03$ \\
\hline mmp 11 & stromelysin-3 & 91 & $6,21 \mathrm{E}-03$ \\
\hline$m r p$ & marcks-related protein & 2803 & $8,04 \mathrm{E}-03$ \\
\hline nptx1 & neuronal pentraxin-1 & 116 & $2,02 \mathrm{E}-03$ \\
\hline$n r \times 3 a$ & neurexin-3-alpha & 82 & $4,00 \mathrm{E}-04$ \\
\hline ntngl & netrin-g1 & 73 & $6,48 \mathrm{E}-03$ \\
\hline pkha6 & pleckstrin homology domain-containing family a member 6 & 152 & $9,60 \mathrm{E}-03$ \\
\hline pkp1 & plakophilin-1 & 78 & $8,14 \mathrm{E}-03$ \\
\hline rrmj3 & rrna methyltransferase 3 & 1440 & 3,47E-03 \\
\hline rrmj3 & rrna methyltransferase 3 & 141 & $7,01 \mathrm{E}-03$ \\
\hline$s 4 a 7$ & sodium bicarbonate cotransporter 3 & 133 & $3,05 \mathrm{E}-05$ \\
\hline $\operatorname{scm} 2 b$ & calcium-binding mitochondrial carrier protein $s-2-b$ & 133 & $6,58 \mathrm{E}-03$ \\
\hline scrb2 & lysosome membrane protein 2 & 3758 & $3,52 \mathrm{E}-05$ \\
\hline smox & spermine oxidase & 236 & $8,16 \mathrm{E}-03$ \\
\hline sp5 & transcription factor sp5 & 120 & $9,40 \mathrm{E}-03$ \\
\hline vis/1 & visinin-like protein 1 & 54 & $7,96 \mathrm{E}-03$ \\
\hline wn10a & protein wnt-10a flags: precursor & 127 & $3,63 \mathrm{E}-03$ \\
\hline
\end{tabular}

in rete tissue of the European eel (Fig. 1). 59\% of cell cycle related genes were transcribed, but also $34 \%$ of genes involved in transport of small molecules and $44 \%$ of genes connected to vesicle transport. Of note, $43 \%$ of the genes involved in signal transduction were transcribed in rete tissue. Of the genes associated with metabolism,
49 out of 140 genes were involved in glucose metabolism and 14 out of 46 genes associated with the pentose phosphate shunt were detected. In addition, 60 out of 233 genes involved in the citric acid cycle and 39 out of 150 genes contributing to the respiratory chain were transcribed in rete tissue. Looking at genes responsible for 


Autophagy
Cell Cycle
Cell-Cell Communication
Cell. Resp. to External Stimul.
Chromatin Organization
Circadian Clock
Developmental Biology
Disease
DNA Repair
DNA Replication
Extrac. Matrix
Gene Expression
Hemostasis
Immune System
Metabolism
Metabolism of Proteins
Metabolism Of RNA
Muscle Contraction
Neuronal System
Organelle Biogenesis
Prog. Cell Death
Protein Localization
Reproduction
Signal Transduction
Transp. Of Small Molecules
Vesicle Transport

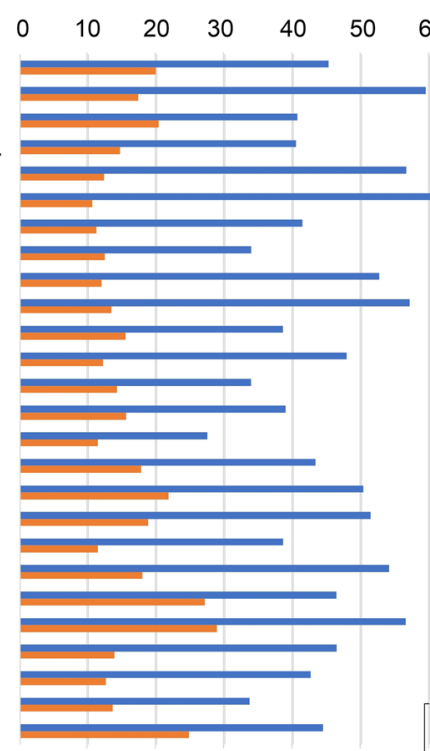

Fig. 1 Percentage of genes of the 25 pathways identified in the Reactome analysis in the transcriptome (blue line) and the proteome (orange line) of European yellow and silver eel rete mirabile tissue. Because only very few genes were differentially expressed between yellow and silver data sets were combined to obtain a clearer picture of genes expressed in rete mirabile tissue. The number gives the total number of genes listed in the Reactome data base for the respective pathway

the formation of the extracellular matrix, 127 out of 330 listed genes were detected in the rete transcriptome.

A more detailed analysis of the transcriptome was restricted to genes transcribed with a relative expression value higher than 50 . Among the transcripts related to the formation of the extracellular matrix, 15 collagen transcripts were detected (cola, coaa, co6a, coca, $\operatorname{co} 4 a, \cos a, \operatorname{cog} a, \operatorname{co} 2 a, \operatorname{cr} a 1 b)$, and also one collagenase transcript (Additional file 1). Additional transcripts of extracellular matrix constituents were 6 laminins (lamc, lama), and basement membrane specific proteoglycan transcripts ( $\mathrm{pgm}$ ) were detected. The transcriptome also contained transcripts of matrix metalloproteinases and of collagenase ( $m m p$, ats).

Searching the transcriptome with respect to transcripts translating into membrane transport proteins (ion transport proteins; channel proteins; membrane ATPases) (Fig. 2; Additional file 2) revealed the presence of 33 transcripts of V-type proton ATPase subunits, coding for 15 different subunits (vata, vatb, vatd, vate, vatf, vatg, vath, vatl, vatm, vato, vpp, vaOd, vaOe, vtc1). The family of calcium channel proteins was also represented by a large number of transcripts (ca2d, cac1h, cac1, cacb, crcm).

Several transcripts of various members of the solute carrier families (SLC) were detected, including transcripts of sodium bicarbonate transport proteins $(s 4 a)$ and transcripts of different SLC families involved in organic anion transport (so2, so3, so5). 6 different monocarboxylate transporter transcripts (mot1, mot4, mot6, $\operatorname{mot} 7, \operatorname{mot} 9, \operatorname{mot} 10)$ were detected, and a number of different glucose carrier transcripts were expressed (gtr 1, gtr3, gtr6, gtr10) (Fig. 2; Additional file 2).

Focusing in particular on signal transduction and receptor related transcripts revealed the presence of receptor type tyrosine-protein phosphatase (ptpr) and of vascular endothelial growth factor receptor $(\nu g f r)$ transcripts. In addition, endothelin receptor transcripts (ednra, ednrb) acetylcholine receptor (acha) and adrenergic receptor ( $a d a$, arbk) were found. Transforming growth factor beta receptor beta (tgbr, tgfa, tgfr) and inositol-trisphosphate receptor (itpr) were also detected in the transcriptome (Additional file 3).

Analysis of the proteome revealed 5289 proteins, out of which only 104 proteins were uncharacterized proteins with yet unknown function (Additional file 4). In the proteome of yellow and silver eels, 74 proteins were differentially expressed, 73 of these proteins had a predicted function (Additional file 5). 67 proteins were reduced in their expression level, but only 2 proteins (synembryn-A and fucolectin-7like) were reduced by more than 3-fold. 7 proteins were about 2-fold elevated in their expression level. Accordingly, the changes in protein abundance between silver and yellow eels were modest. Noteworthy, among the proteins significantly affected were mimecan and several collagens, 


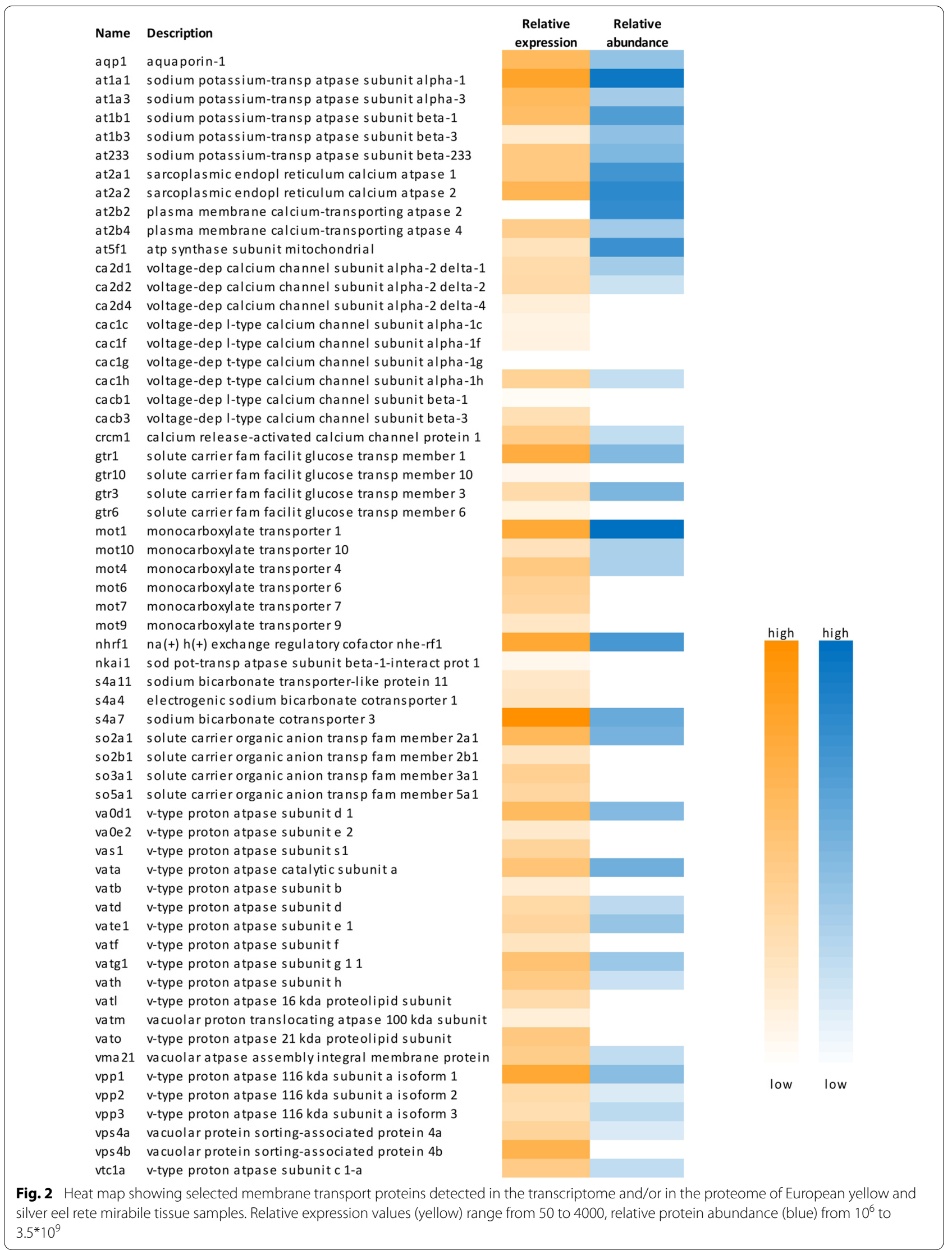


components of the extracellular matrix (Additional file 5), but no membrane transport proteins.

For a more detailed data analysis of proteins that are expressed in rete capillaries, the procedure developed for the transcriptome was adopted and the data sets of yellow and silver eels were combined. Pathway analysis using the Reactome pathway browser revealed that, on the basis of 5185 proteins with known function, in 25 pathways between $10 \%$ and $27 \%$ of the Reactome database listed genes were translated in rete tissue of the European eel (Fig. 1). Overall, 36\% of the genes detected in the transcriptome were also detected in the proteome. The lowest match with only $17 \%$ was detected for circadian clock genes, the highest agreement was present for genes related to apoptosis with $58 \%$. Table 2 shows the overlap of proteome and transcriptome data for the specific physiological functions addressed in this analysis. The highest overlap was detected for ATPases. For $84 \%$ of the detected transcripts the appropriate proteins were found. On the other hand, only $41 \%$ of the transcripts coding for receptor proteins the appropriate proteins could be detected. In Fig. 3 for all genes detected in both, the transcriptome as well as in the proteome, relative mRNA expression values are plotted versus the relative protein abundance. Relative mRNA expression of most genes was in the range $10^{2}$ to $10^{4}$, while protein abundance varied between $10^{5}$ and $10^{8}$. Spearman's rank-order correlation was run to determine the relationship between mRNA expression and protein abundance. There was a moderate, positive correlation between mRNA expression and protein abundance, which was statistically significant $(\mathrm{rs}(2851)=0.422, \mathrm{p}=0.000000200)$.

Searching the description of the annotated proteins for terms related to the extracellular matrix a large number of proteins were detected (Additional file 1). Consistent with the transcriptome, these proteins included a number of collagens (Co6a, Coca, Coea,

Table 2 Number of genes in specific functional groups detected in the transcriptome and in the proteome (Trans. + Prot.), and the number of genes detected either in the transcriptome or in the proteome (Trans. or Prot.). The fractional overlap between transcriptome and proteome is given as \% value

\begin{tabular}{|c|c|c|c|}
\hline & Trans. + Prot. & Trans. or Prot. & \% \\
\hline Channel & 54 & 41 & 57 \\
\hline ATPase & 175 & 34 & 84 \\
\hline Extr. matrix & 130 & 176 & 42 \\
\hline Metabolism & 2147 & 1404 & 60 \\
\hline Mitochondria & 946 & 336 & 74 \\
\hline Ion transport & 523 & 351 & 60 \\
\hline Receptor & 257 & 369 & 41 \\
\hline
\end{tabular}

Co18a, Col18a, Cola1) and several laminins (Lama, Lamc). In contrast to the transcriptome, disintegrin and metalloproteinase (Ats) were not detected in the proteome. In Fig. 4, the relative mRNA expression of the extracellular matrix protein families is plotted versus the relative protein abundance. In addition to laminins and the collagen protein family, fibulins and a proteoglycan were detected, and all families were present with similar relative expression values and protein abundances.

Focusing on membrane transport (Fig. 2; Additional file 2), proteins contributing to 13 subunits of V-type proton ATPase were isolated (Vaod, Vata, Vatd, Vate, Vatf, Vatg, Vath, Vma21, Vpp, Vps, Vtc). Both subunits of $\mathrm{Na}^{+} / \mathrm{K}^{+}$-ATPase were detected (At1a1, At1a3; At1b1, At1b3, At233), and also subunits of plasma membrane $\mathrm{Ca}^{2+}$-ATPase (At2b2, At2b3, At2b4, Atp2c1) and sarcoplasmic reticulum $\mathrm{Ca}^{2+}$-ATPase (At2a1, At2a2) (Additional file 2). In the family of solute carrier proteins, the proteome included two glucose transport proteins (Gtr1, Gtr3), as well as several monocarboxylate carriers (Mot1, Mot4, Mot10). The heat map illustrates that genes expressed with high mRNA copy numbers typically were also highly expressed at the protein level, like, for example Gtr1 or Mot1. This was also observed for the highly expressed sodium bicarbonate cotransporter (S4a7) and a number of subunits of various calcium channel proteins (Ca2d1, Ca2d2, Cac1h), also present in the transcriptome at intermediate levels. Other calcium channel subunits present with a relatively low expression value in the transcriptome were not detected in the proteome (Fig. 2). Plotting the relative mRNA expression versus the protein abundance revealed the presence of a large number of membrane transport proteins and of a remarkable number of ATP-dependent transport proteins including the presence of most subunits of mitochondrial $\mathrm{F}_{1} / \mathrm{F}_{0}$-ATP synthase (Fig. 5). Most of these genes were expressed with a relative mRNA expression of $10^{2}$ to $10^{4}$ and a protein abundance of $10^{6}$ to $10^{8}$.

A large number of proteins involved in glucose metabolism were identified (including Hkdc1, Hxk1, Aldr, K6pp, F16p1, F263, Gpda, Ldha, Ldhb, Kpbb), but also two proteins involved in the pentose phosphate pathway (6Pgd, G6pd). Proteins involved in mitochondrial energy metabolism included, for example, Acly, Dhsa, Dhsb, Idhc, Idh3, Ndua, Ndub, Nduc, and Ndus (Fig. 6). Overall, 459 mitochondrial proteins were detected in the proteome, including 39 proteins contributing to cytochrome complex formation. 139 of the detected mitochondrial proteins were involved in the biological process 'electron transport'.

Noteworthy was the presence of proteins connected to the degradation of reactive oxygen species, including 


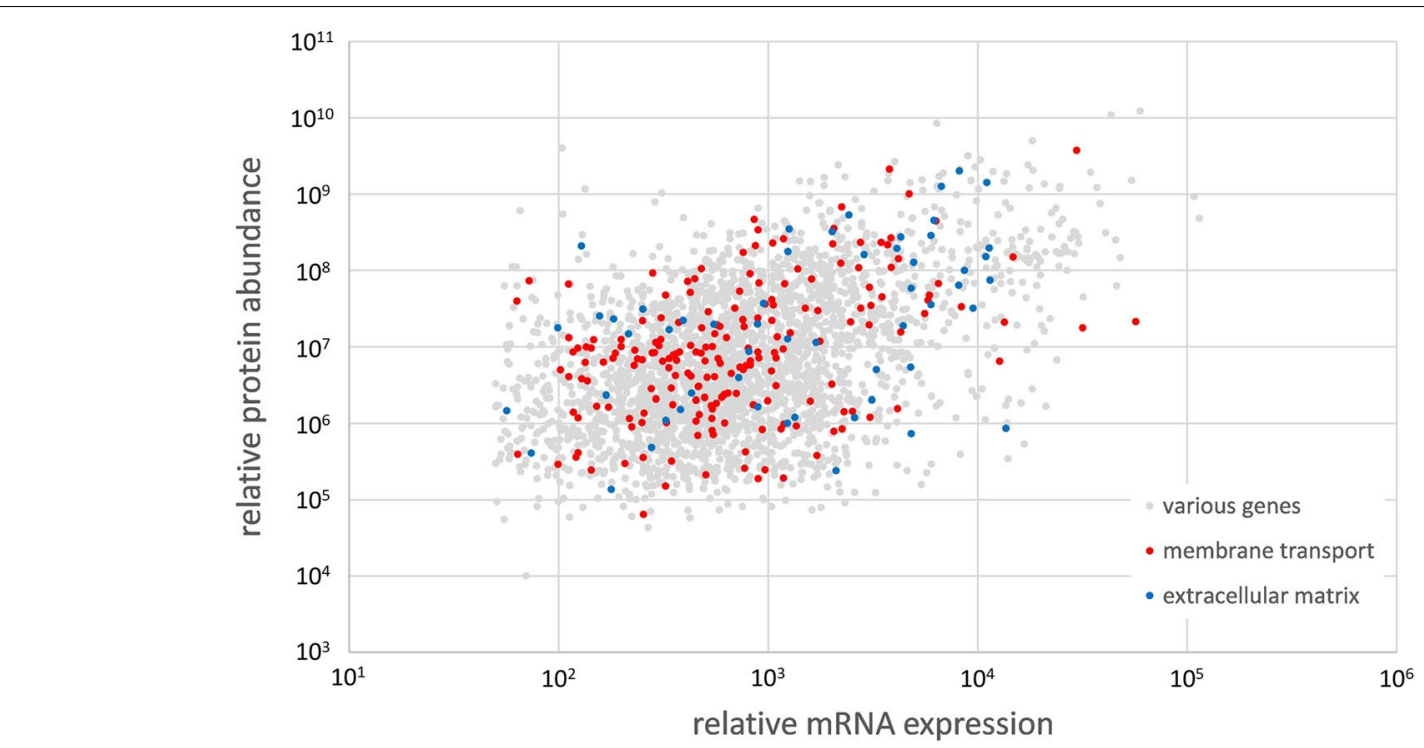

Fig. 3 Relative mRNA expression plotted versus the relative protein abundance of all genes detected in the proteome as well as in the transcriptome of European yellow and silver eel rete mirabile tissue samples. Genes associated with membrane transport are marked in red, genes associated with the extracellular matrix are marked in blue. Spearman's rank-order correlation: rs (2851) $=0.422, p=0.000000200$

catalase (Cata), glutathione related proteins (Gshr, Gstp, Gstt), superoxide dismutase (Sodm), peroxiredoxin (Prdx, Tdx), and thioredoxin (Txd, Txnd).

In line with the transcriptome, the proteome included a number of receptor-type tyrosine-protein phosphatases (PTPR). In addition, receptor-tyrosine kinases (Tie1, Tie2, Tyro3), endothelin receptor (Ednra, Ednrb), beta adrenergic receptor kinase (Aarbk2) and atrial natriuretic peptide receptor (Anpra) were expressed at the protein level. Glucocorticoid receptor (Gcr) and insulin receptor short (Insr) were also found (Additional file 3).

\section{Discussion}

Analysis of the transcriptome and of the proteome revealed presence of a large number of proteins of the families of SLC membrane transport proteins and of

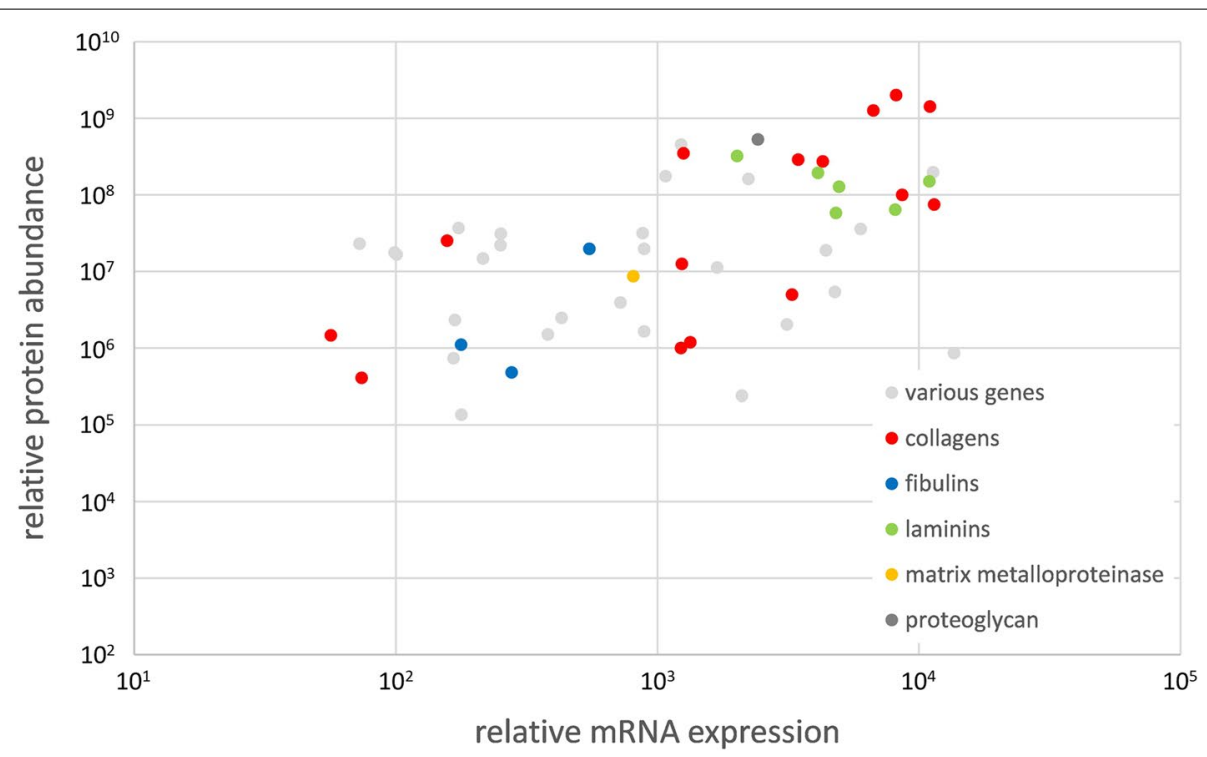

Fig. 4 Relative mRNA expression plotted versus the relative protein abundance of selected extracellular matrix genes detected in the proteome as well as in the transcriptome of European yellow and silver eel rete mirabile tissue samples. Different families of extracellular matrix proteins are color coded 


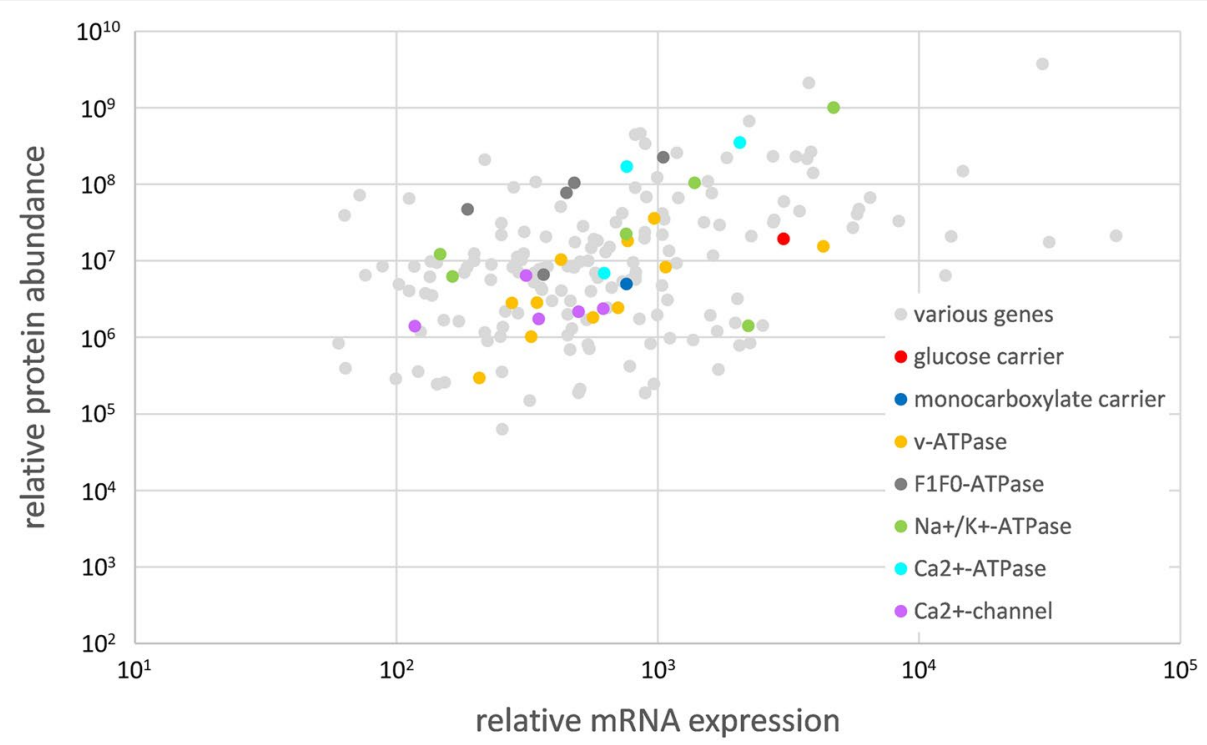

Fig. 5 Relative mRNA expression plotted versus the relative protein abundance of selected genes coding for proteins involved in membrane transport detected in the proteome as well as in the transcriptome of European yellow and silver eel rete mirabile tissue samples

membrane bound ATPases, which was in line with our hypothesis that the countercurrent concentrating capacity of the rete mirabile would be supported by the expression of solute transport proteins in rete mirabile capillaries. Our hypothesis that during silvering the expression of these proteins would be enhanced, however, was not supported by the data.

\section{General comparison of transcriptome and proteome data}

Overall comparison of the transcriptome and the proteome revealed that the number of proteins isolated in the proteome amounted to about $16 \%$ of the identified transcripts, and most of the detected proteins had a predicted function. In fish, the large number of transcripts certainly is related to the whole genome duplications encountered during evolution [33, 34]. Analysis of the proteome of European eel gas gland cells resulted in the identification of 6223 proteins [35], a value about $20 \%$ higher than the number of proteins isolated from rete cells. While in gas gland cells, all fractions have been analyzed [35], our rete cell analysis was focused on the membrane fraction, so that cytosolic proteins probably were underrepresented, which may have contributed to the lower number of proteins identified in the rete.

In contrast to previous studies on swimbladder gas gland cells, in which transcriptome and proteome data have been collected from different tissue samples [3537], in our present study both data sets have been collected from the same tissue samples, allowing for an analysis of the correlation between protein and mRNA expression. The results revealed that in rete tissue, the overall correlation between protein and mRNA was modest with a Spearman's correlation of 0.422 , ( $\mathrm{p}=$ 0.000000200 ).

Focusing on the overlap between transcriptome and proteome within functional groups, the results varied remarkably. While for mitochondrial proteins and ATPases an overlap of $74 \%$ and $84 \%$ was detected, respectively, less than $50 \%$ of the transcripts coding for receptor proteins were detected in the proteome, and overall, the overlap was even lower with a value of $36 \%$. While in yeast cells, a good correlation between detected protein copies and mRNA copies has been reported [38], other studies indicated a poor correlation between mRNA and protein levels in different tissues [39-41].

\section{The effect of silvering}

In the eel, silvering is accompanied by an elongation of the rete mirabile, which improves the countercurrent concentration capacity $[27,28]$. Silver eels, during their spawning migration, experience significantly larger hydrostatic pressures than yellow eels, dwelling in freshwater rivers and lakes. It therefore was expected that the elevated gas partial pressures necessary to fill the swimbladder at high hydrostatic pressure would require an increased countercurrent concentrating capacity of the rete mirabile and thus would affect the expression of membrane transport proteins. In previous studies it has already been demonstrated that silvering is associated with significant changes in the transcriptome and the proteome of swimbladder gas gland cells [35-37]. This obviously was not the case in the rete mirabile tissue as 
Name Description

6pgd 6-phosphogluconate decarboxylating

aakb1 5 -amp-activated protein kinase subunit beta- 1

aakg1 5 -amp-activated protein kinase subunit gamma-1

aakg2 5 -amp-activated protein kinase subunit gamma-2

aapk1 5 -a mp-activ protein kinase catalyt subunit alpha-1

acly atp-citrate synthase

aldoa fructose-bisphosphate aldolase a

aldoc fructose-bisphosphate aldolase c

aldr aldose reductase

c560 succinate dehydrogenase cytochrome b560 mitoch

cahz carbonic anhydrase

cata catalase

cy24b cytochrome b-245 heavy chain

dhe3 glutamate mitochondrial

dhsa succinate dehydrogenase flavoprotein mitoch

dhsb succinate dehydrogenase iron-sulfur mitochondrial

dhsdb succinate dehyd cytochrome b small subunit mitoch

f16p1 fructose--bisphosphatase 1

f263 6-phosphofructo-2-kinase fructose-biphos phatase 3

fumh fumarate mitochondrial

g6pd glucose-6-phosphate 1-dehydrogenase

g6pi glucose-6-phosphate isomerase

gde1 glycerophosphodiester phosphodiesterase 1

glu2b glucosidase 2 subunit beta

gpd1l glycerol-3-phos phate dehydrogenase 1-like protein

gpda glycerol-3-phosphate dehydrogenase cytoplasmic

gpdm glycerol-3-phosphate mitochondrial

gpx1 glutathione peroxidase 1

gpx4 phospholipid hydroperoxide glutathione mitoch

gshr glutathione mitochondrial

gstp2 glutathione $s$-transferase $\mathrm{p} 2$

gstt1 glutathione $s$-transferase theta- 1

hkdc1 hexokinase hkdc1

hxk1 hexokinase-1

idh3a isocitrate dehydrogenase subunit mitochondrial

idh3b isocitrate dehydrogenase subunit mitochondrial

idhc isocitrate dehydrogenase cytoplasmic

idhg1 isocitrate dehydrogenase subunit gamma mitochl

idhp isocitrate dehydrogenase mitochondrial

k6pp 6-phosphofructokinase type c

kad2 adenylate kinase mitochondrial

kpb1 phosphorylase b kinase regul subunit skeletal muscle

$\mathrm{kpbb}$ phosphorylase $\mathrm{b}$ kinase regulatory subunit beta

kpyk pyruvate kinase muscle isozyme

Idha I-lactate dehydrogenase a chain

Idhb I-lactate dehydrogenase b chain

ncpr nadph--cytochrome $\mathrm{p} 450$ reductase

ndua2 nadh dehydrogenase 1 alpha subcomplex subunit 2 ndua 4 nadh dehydrogenase 1 alpha subcomplex subunit 4 ndua 5 nadh dehydrogenase 1 alpha subcomplex subunit 5 ndua 6 nadh dehydrogenase 1 alpha subcomplex subunit 6 ndua 7 nadh dehydrogenase 1 alpha subcomplex subunit 7 ndua 8 nadh dehydrogenase 1 alpha subcomplex subunit 8 ndua 9 nadh dehydrog 1 alpha subcomplex subunit mitoch nduaa nadh dehydrog 1 al pha subcomplex subunit mitoch nduac nadh dehydrog 1 alpha subcomplex subunit 12

ndub2 nadh dehydrogenase 1 beta subcomplexsubunit 2 ndub3 nadh dehydrogenase 1 beta subcomplex subunit 3 ndub4 nadh dehydrogenase 1 beta subcomplex subunit 4 ndub6 nadh dehydrogenase 1 beta subcomplex subunit 6 ndub8 nadh dehydrog 1 beta subcomplex subunit mitoch ndub9 nadh dehydrogenase 1 beta subcomplex subunit 9 nduba nadh dehydrogenase 1 beta subcomplex subunit 10 nduc1 nadh dehydrogenase 1 subunit mitochondrial nduc2 nadh dehydrogenase 1 subunit c2

ndus 1 nadh-ubiquinone oxidoreductase $75 \mathrm{kda}$ mitoch ndus 2 Nadh-dehydrog iron-sulfur protein mitochondria ndus 3 nadh dehydrog iron-sulfur protein mitochondrial ndus 4 nadh dehydrog iron-sulfur protein mitochondrial ndus 5 nadh dehydrog iron-sulfur protein 5

ndus 6 nadh dehydrog iron-sulfur protein mitochondrial ndus 8 nadh dehydrog iron-sulfur protein mitochondrial nduv2 nadh dehydrogenase flavoprotein mitochondrial nduv3 nadh dehydrogenase flavoprotein mitochondrial

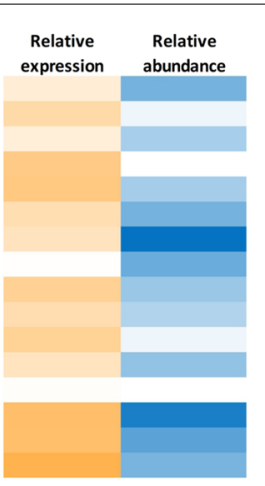

pckgm phos phoenolpyruvate carboxykinase mitochondrial pgam1 phosphoglycerate mutase 1

pgm1 phosphoglucomutase-1

pgm2 Phosphoglucomutase-2

pgm5 phosphoglucomutase-like protein 5

phkg2 phosphorylase b kinase gamma catal testis liver is of prdx1 peroxiredoxin-1

prdx2 peroxiredoxin-2

prdx3 thioredoxin-dependent peroxide mitochondrial

prdx4 peroxiredoxin-4

prdx5 peroxiredoxin-mitochondria

prdx6 peroxiredoxin-6

pyc pyruvate mitochondrial

qcr1 cytochrome b-c1 complex subunit mitochondrial

qcr2 cytochrome b-c1 complex subunit mitochondrial

qorl1 quinone oxidoreductase-like protein 1

sodm superoxide dismutase mitochondrial

$\operatorname{tdx}$ peroxiredoxin

tmx1 thioredoxin-related transmembrane protein 1

tmx4 thioredoxin-related transmembrane protein 4

tpisb triosephosphate isomerase b

trxr3 thioredoxin reductase 3

txd12 thioredoxin domain-containing protein 12

txnd5 thioredoxin domain-containing protein 5
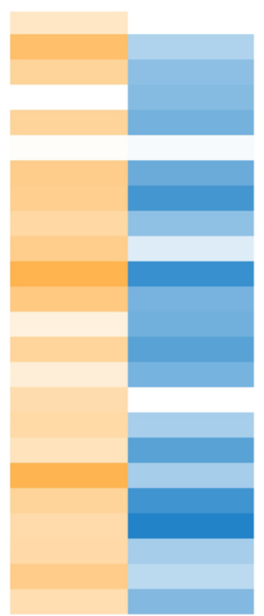

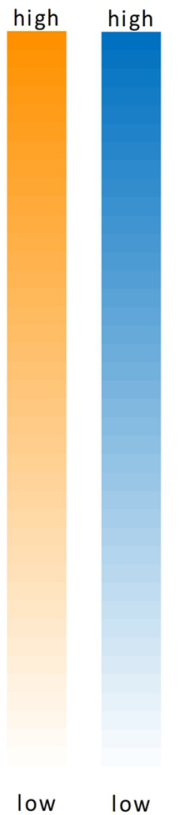

Fig. 6 Heat map showing selected proteins involved in cellular energy metabolism detected in the transcriptome and/or in the proteome of European yellow and silver eel rete mirabile tissue samples. Relative expression values (yellow) range from 50 to 30,000 , relative protein abundance (blue) from $10^{6}$ to $1.2^{*} 10^{10}$ 
only about $0.2 \%$ of the transcripts were significantly different in silver eels at the level of $p<0.01$, and using $\mathrm{p}$-adjust for the analysis none of these genes was significantly different. Analysis of the gas gland cell transcriptome of yellow and silver eels revealed 646 differentially expressed genes at the level of $\mathrm{p}<0.01$ [36].

Our proteome analysis confirmed the analysis of the transcriptome. Less than $1 \%$ of the proteins were significantly affected in the rete of silver eels, the change in abundance was moderate, with only two genes reduced more than 3-fold in their relative abundance. None of the membrane transport proteins was affected. Our data thus did not reveal large differences in rete gene expression between yellow and silver eels. Our tissue samples were collected from yellow eels and from silver eels after completing the transition, not during silvering. In silver eels, the length of the rete capillaries is increased [27, 28], resulting in a larger overall surface area available for back-diffusion and countercurrent concentration. Our data thus suggest that in contrast to our expectation during silvering hardly any changes in the area specific transport capacity are encountered. Increasing length and thus surface area of the rete capillaries [27, 28] increases tissue mass, but this apparently was not associated with a modulation of gene expression. Increasing the surface area of the rete appears to be the main effect allowing for an enhanced countercurrent concentration ability in silver eels.

\section{Membrane transport proteins}

We hypothesized that in the rete the countercurrent concentrating capacity would be supported by the expression of specific membrane transport proteins facilitating back-diffusion of small molecules (ions and metabolites) from the venous to the arterial side. The presence of a large number of ion transporter and of monocarboxylate transport proteins indeed suggested that rete capillaries are not only passive exchangers, but transport of ions and metabolites can be supported by specific transport proteins. Presence of monocarboxylate transport (Mot) proteins (=MCT proteins; SLC16) was in line with the previously detected back-diffusion of lactate from venous to arterial rete capillaries [14]. Mct 1 and $m c t 4$ mRNA has also been detected in arterial capillaries of the rete mirabile and in gas gland cells of fugu (Takifugu rubripes) by in situ hybridization [42], suggesting that the expression of transport proteins is a widespread phenomenon in swimbladder rete mirabile tissue. Back-diffusion of lactate has been shown to be advantageous for the salting out effect [17], and this is particularly important for the concentration of inert gases. The transport proteins identified in rete endothelial cells therefore may contribute to back-diffusion of solutes and elevate the inert gas partial pressure, which would allow for countercurrent concentration of inert gases [16]. Numerous subunits of a V-type proton ATPase have been detected in the transcriptome as well as in the proteome, and a V-type proton ATPase may contribute to back-diffusion of protons from the venous to the arterial side of the rete and support the acidification of arterial rete capillaries. Back-diffusion and countercurrent concentration of acidic metabolites has been shown to enhance blood acidification, switching on the Root effect $[6,21]$.

Remarkable was the presence of a large number of calcium channel protein transcripts and proteins. In addition, various subunits of cytoplasmic calcium ATPase as well as of endoplasmic reticulum calcium ATPase (SERCA) were identified, indicating extensive $\mathrm{Ca}^{2+}$ movements between the endoplasmic reticulum and the cytoplasm, and also between the extracellular space and the cytoplasm. These movements probably are of regulatory importance, perhaps influencing the tightness of the connection between endothelial cells. This would be in line with the presence of a large number of receptor tyrosine kinase and phosphatases, including the angiopoietin receptors TIE1 and TIE2. Angiopoietin is a crucial growth hormone for angiogenesis, which is required for elongation of rete capillaries, as observed during silvering in eels. Many receptor tyrosine kinases are receptors for growth hormones, and reversible receptor tyrosine kinase phosphorylation is a very important mechanism contributing to cell adhesion, cell proliferation and cell-cell interaction [43]. $\mathrm{Ca}^{2+}$ movements could also contribute to the control of blood flow through the rete, and thus the swimbladder tissue. Noteworthy in this context was the detection of endothelin receptor, beta-adrenergic receptor kinase and of the ANP receptor. The activity of smooth muscle cells at the entrance of the rete could perhaps modify perfusion resistance and thus control blood flow through the swimbladder. The secretory activity of swimbladder tissue has been shown to be dependent on blood flow through the swimbladder [44].

\section{Energy metabolism}

Transport of ions or solutes in a second step often involves the activity of $\mathrm{Na}^{+} / \mathrm{K}^{+}$-ATPase, and the subunits of this ATPase have been detected in the transcriptome as well as in the proteome. The ATP-consumption of these ATPases can be covered by oxidative phosphorylation as indicated by the presence of $\mathrm{F}_{1} \mathrm{~F}_{0}$-ATP synthase.

A large number of genes related to energy metabolism were detected in rete endothelial cells, including many enzymes of the glycolytic pathway. This was expected, as studies by Rasio $[45,46]$ suggested that the energy metabolism of rete endothelial cells is almost exclusively based on glycolysis and lactate production. Our results, 
however, also show the presence of the two key enzymes of the pentose phosphate shunt (PPS). The PPS results in the generation of $\mathrm{NADPH}_{2}$, which is required for the glutathione metabolism and thus involved in ROS degradation, which appears to be important for rete tissue (see below). In addition, our data reveal the presence of a large number of mitochondrial transcripts with high transcript numbers: 21 transcripts of various ATP synthase subunits and 41 cytochrome transcripts. Also, ADP/ATP translocase was among the mitochondrial transcripts with highest transcript values. This was in line with the detection of mitochondrial proteins including key enzymes of the citric acid cycle, NADH dehydrogenase and cytochrome oxidase from the respiratory chain, many subunits of $F_{1} F_{0}$-ATP synthase and ADP/ ATP translocase. Aerobic ATP production is much more efficient than anaerobic ATP formation, and this appears to be related to the presence of various ATP dependent transport proteins, including $\mathrm{Na}^{+} / \mathrm{K}^{+}$-ATPase, V-type proton ATPase and $\mathrm{Ca}^{2+}$-ATPases located in cell membranes as well as in the endoplasmic reticulum. We therefore conclude that rete endothelial cell metabolism is not restricted to anaerobic ATP formation, but also includes aerobic ATP production in the oxidative metabolism.

\section{Extracellular matrix}

Rete capillaries are surrounded by thin basement membranes [22, 47], and a large number of collagens and laminins have been detected in the transcriptome as well as in the proteome. Basement membranes of the European eel have been described as layered structures containing numerous microfibrils [22], and elongation of rete capillaries requires additional extracellular matrix proteins. Concomitant with basement membranes constituents, a number of matrix metalloproteases have been identified at the mRNA and at the protein level, which are required for maintenance and reconstruction of the basement membrane.

\section{Defense of reactive oxygen species}

The swimbladder has been shown to contain high concentrations of oxygen, and with increasing depth increasing hyperoxic conditions prevail [48-50]. Analysis of the ROS defense capacity of swimbladder tissue of six marine fish suggested that a high oxygen content of the swimbladder is correlated with a high superoxide dismutase (SOD) activity [51]. A recent study on the European eel confirmed a high ROS defense capacity and showed that SOD activity in swimbladder tissue of the yellow eel was significantly higher than in muscle tissue [52]. During silvering, a process preparing the yellow eel for the spawning migration to the Sargasso Sea, SOD activity was even elevated. The high oxygen partial pressures required to fill the swimbladder are generated in the rete mirabile. Therefore it is not surprising that rete endothelial cells also are characterized by a high ROS defense capacity, as shown in the present study. Catalase, superoxide dismutase, glutathione related enzymes, peroxiredoxin and also thioredoxin were all detected at the mRNA as well as at the protein level, and the significant changes observed in the proteome of silver eels include slight elevations in reactive oxygen species degrading enzymes (SOD, peroxiredoxin, glutathione-S-transferase). These results confirm the conclusion that fish tissues exposed to high oxygen partial pressures require a high ROS defense capacity [53].

In summary, our data indicated that in swimbladder rete tissue a remarkable set of transport proteins was expressed, and in this respect the transcriptome and the proteome data were remarkably consistent. This suggested that protein mediated transport significantly supports back-diffusion of ions and metabolites in the rete mirabile, which enhances the countercurrent concentrating capacity of the rete. Silvering, however, was connected to only moderate changes in protein expression and did not affect the expression of membrane transport proteins. We therefore have no indication for an improvement of area specific transport capacities of the rete associated with silvering. The main effect of silvering on the countercurrent concentrating capacity of the rete appears to be achieved by increasing the total surface area. As already demonstrated for swimbladder tissue, the hyperbaric oxygen tensions generated in the rete mirabile coincide with a high ROS defense capacity in rete cells.

\section{Methods}

Six yellow and six silver female eels were caught by commercial fishermen in Lake Constance, Bregenz, Austria, with bottom traps. They were transferred to the Institute of Zoology at the University of Innsbruck and kept in the freshwater aquarium until sampling the tissue. Table 3 summarizes the morphometrics of yellow and silver eels used for the experiments.

\section{Preparation of rete tissue}

Under anesthesia with 2-Phenoxyethanol $\left(1 \mathrm{ml}^{*} \mathrm{~L}^{-1}\right)$ eels were decerebrated and spinally pithed. Eels were placed into an 'eel holder', as described by Pelster et al. [54]. The gills were irrigated with well-oxygenated tap water (flow rate 4-5 $\mathrm{L}^{*} \mathrm{~min}^{-1}$ ). The body wall was opened ventrally, the swimbladder was exposed and carefully freed from connective tissue. Artery and vein at the heart pole of the retia mirabilia were carefully separated and occlusively cannulated using PE50 and PE60 catheters, respectively. Rete vessels were perfused 
Table 3 Morphometrics of European eels presented as mean \pm $\mathrm{SD}$, silvering index according to Durif et al. (64), and ocular index according to Pankhurst (65)

\begin{tabular}{lll}
\hline & Yellow eels $(\mathbf{n}=\mathbf{6})$ & Silver eels $(\mathbf{n}=\mathbf{6})$ \\
\hline Body mass $[\mathrm{g}]$ & $392.7 \pm 149.1$ & $1037.5 \pm 327.1$ \\
Body length $[\mathrm{cm}]$ & $65.3 \pm 7.5$ & $86.5 \pm 6.5$ \\
Pectoral fin length $[\mathrm{mm}]$ & $27.6 \pm 3.9$ & $41.6 \pm 2.6$ \\
Horizontal eye diameter $[\mathrm{mm}]$ & $6.8 \pm 0.8$ & $10.5 \pm 1.0$ \\
Vertical eye diameter $[\mathrm{mm}]$ & $6.3 \pm 0.6$ & $10.2 \pm 0.8$ \\
Silver Index & $2.5 \pm 0.5$ & $4.5 \pm 0.5$ \\
Ocular Index & $5.2 \pm 0.5$ & $9.8 \pm 1.1$ \\
\hline
\end{tabular}

with heparinized (100 i.u* $\mathrm{ml}^{-1}$ ) saline solution containing (in mmol* $\mathrm{L}^{-1}$ ) $\mathrm{NaCl}, 129 ; \mathrm{KC} 1,5 ; \mathrm{MgSO}_{4}, 0.9$; $\mathrm{CaCl}_{2}, 1.1$; glucose, 15 . Perfusion of rete vessels was controlled by continuous binocular inspection and both retia mirabilia were dissected immediately after total clearance of blood cells. Half of the tissue was blotted dry on absorbent paper, shock frozen in liquid nitrogen and stored at $-80^{\circ} \mathrm{C}$ until further use for analysis of protein expression. The second half was transferred into $1 \mathrm{ml}$ RNAlater ${ }^{\mathrm{TM}}$ solution (Invitrogen by Thermo Fisher Scientific Inc., Waltham, MA, USA) and immediately shock frozen in liquid nitrogen for analysis of the transcriptome.

\section{RNA isolation and Illumina RNAseq analysis}

Total RNA of rete mirabile tissue of five yellow and six silver eels was isolated using the Qiagen miRNeasy Mini kit and a TissueRuptor according to the manufacturer's instructions (Qiagen, Venlo, Netherlands). Quality and integrity of the isolated RNA were checked on an Agilent Bioanalyzer 2100 total RNA Nano series II chip (Agilent, Amstelveen, Netherlands). The Illumina Truseq library prep started with polyA+ RNA selection step, thereby selecting against rRNA. Illumina RNAseq libraries were prepared from $0.5 \mu \mathrm{g}$ total RNA using the Illumina TruSeq Stranded mRNA Library Prep according to the manufacturer's instructions (Illumina Inc. San Diego, CA, USA). All RNAseq libraries (150-750 bp inserts) were sequenced using an Illumina NovaSeq6000 system as $2 \times 150$ nucleotides paired-end reads or an Illumina HiSeq2500 system as $1 \times 50$ nucleotide single-reads according to the manufacturer's protocol. Image analysis and base calling were done using the Illumina pipeline.

\section{Illumina data processing}

Data processing was performed as described previously $[55,56]$. Briefly, reads (16 million per sample) were aligned to the draft genome sequence of European eel [32] using TopHat (version 2.0.13) https://ccb.jhu.edu/ software/tophat/index.shtml [57]. Secondary alignments of reads were excluded by filtering the files using SAMtools (version 1.2 using htslib 1.2.1) [58]. Aligned fragments per predicted gene (also referred to as transcripts) were counted from SAM alignment files using the Python package HTSeq (version 0.6.1p1) https://readthedocs. org/projects/htseq/ [59]. To enable comparisons across samples, fragment counts were corrected for the total amount of sequencing performed for each sample. As a correction scaling factor, library size estimates, determined using the R/Bioconductor (release 3.3.2) package DESeq https://bioconductor.riken.jp/packages/3.4/bioc/ html/DESeq.html [60], were employed. Read counts were normalized by dividing the raw counts obtained from HTSeq https://htseq.readthedocs.io/en/master/insta ll.html by its scale factor. The term "relative expression value" refers to these normalized read counts.

The Reactome database (https://reactome.org) [61] was used for classification of genes into broad pathways. For a detailed pathway and biological process analysis of expressed genes, analysis of the transcriptome was limited to transcripts with a base mean relative expression value above 50 copies in yellow and silver eel rete tissue. The Description of the transcript, GO biological process and molecular function were searched for genes related to a specific metabolic pathway or transport activity (like, for example, metabolic process, receptor, membrane transport, ion transport, channel, ATPase), and the GO cellular component was searched for genes related to a specific cellular structure or organelle (like, for example, extracellular matrix or mitochondrial). In a second step, differentially expressed genes between rete tissue from yellow and silver eels were identified using DESeq, the cut-off for significance was set to $\mathrm{p}<0.01$.

\section{Protein extraction, digestion and ITRAQ labeling}

Sample preparation was performed as previously described with an additional iTRAQ labeling of peptides [35]. Briefly, frozen tissues of 12 samples (6 biological replicates for yellow and for silver eels, respectively) were homogenized and centrifuged at $1000 \times \mathrm{g}$ for $10 \mathrm{~min}$ at $4{ }^{\circ} \mathrm{C}$ to obtain a pellet containing debris and nuclear components. The supernatant was removed and centrifuged again at $15,000 \times \mathrm{g}$ for $30 \mathrm{~min}$ at $4{ }^{\circ} \mathrm{C}$ to separate the components into a membrane fraction (pellet) and cytosolic fraction (supernatant). The membrane pellets were reconstituted in $60 \mu \mathrm{l}$ of a chaotropic buffer containing $7 \mathrm{M}$ urea, $2 \mathrm{M}$ thiourea, 4\% CHAPS, $100 \mathrm{mM}$ DTT, and $50 \mathrm{mM}$ TEAB. Protein amounts were estimated using a Bradford protein assay (Carl Roth $\mathrm{GmbH}, \mathrm{K} 880$ ). Protein 
samples $(100 \mu \mathrm{g})$ were digested with Trypsin $(1: 50 \mathrm{w} / \mathrm{w}$, Promega, V5117) using the FASP procedure [62].

Resulting peptides were enriched and desalted using C18 packed pipette tips (Pierce, \#87,784), lyophilized, and reconstituted in $90 \mu \mathrm{l} 100 \mathrm{mM}$ TEAB buffer. An aliquot of $18 \mu \mathrm{l}$ per sample was mixed with iTRAQ4plex labeling reagent following the manufacturer's instructions (Applied Biosystems). Samples were incubated for $3 \mathrm{~h}$ at room temperature, dried down in a Speed Vac and reconstituted in $75 \mu \mathrm{L} 0.1 \%$ TFA. The contents of four differentially iTRAQ labeled samples were combined and separated using high $\mathrm{pH}$ reversephase spin columns (Thermo Fisher, \#84,868) into eight fractions.

\section{LC-MS/MS analysis and database searching}

Peptides from each fraction were analyzed by LC-MS within $2 \mathrm{~h}$ gradients using a Dionex Ultimate 3000 system (Thermo Fisher Scientific) coupled to a Q-Exactive Plus mass spectrometer (Thermo Fisher Scientific) that was set to operate in data-dependent mode. Details were as described previously [63]. Fragment spectra were matched against the draft genome sequence of the European eel [32] [protein database (34,018 sequences, https://www.ncbi.nlm.nih.gov/assembly/GCA_00069 5075.1] using Sequest via the Proteome Discoverer 2.2 software (Thermo Scientific, USA). The search parameters were as follows:

Enzyme specificity was set to trypsin, carbamidomethylation of cysteine was set as a fixed modification. Oxidized methionine, acetylation and/or methionine loss at the protein $\mathrm{N}$-terminus, and iTRAQ 4plex label at lysine residues and at the peptide $\mathrm{N}$-terminus were set as variable modifications. A maximum of two missed cleavages were allowed. The required false positive rate was set to $1 \%$ at the peptide and at the protein level, respectively, and was calculated via the Percolator node.

\section{iTRAQ-based protein quantitation}

For quantitation of proteins the fold changes were calculated based on iTRAQ reporter ion intensities present in MS2 scans ( $\mathrm{m} / \mathrm{z} 114,115,116$, and 117). The reporter ion intensities were extracted using the default software settings: Only peptides that were unique to a given protein or protein group were considered for quantitation. Fragment ion tolerance was set to $20 \mathrm{ppm}$ for the most confident centroid peak and co-isolation threshold was set to $50 \%$. Normalization was performed such that the total sum of the reporter ion intensities was the same for all four sample channels. To determine differences in protein expression Significance B (Maxquant/Perseus software), a $P$ value depending on protein intensity and protein ratio was used. Settings were: Two-tailed test, FDR threshold value 0.05, Benjamini-Hochberg correction for multiple hypothesis testing was applied.

\section{Data analysis}

The Reactome database (https://reactome.org) [61] was used for classification of detected proteins into broad pathways. The detailed pathway and biological process analysis of expressed proteins followed the procedure described for the transcriptome analysis (see above). A Spearman's rank-order correlation was run to determine the relationship between mRNA expression and protein abundance.

\section{Supplementary Information}

The online version contains supplementary material available at https://doi. org/10.1186/s12864-021-08180-2.

\section{Additional file 1}

Additional file 2.

Additional file 3.

Additional file 4.

Additional file 5 .

\section{Acknowledgements}

Not applicable.

\section{Authors' contributions}

VD and GS prepared the tissue samples, experimentation, data analyses, reading and commenting on the manuscript, $\mathrm{RD}$ transcriptome preparation, reading and commenting on the manuscript, KF and BS, preparation of the proteome, reading and commenting on the manuscript, BP design of the study, experimentation, data analyses, writing, funding. The author(s) read and approved the final manuscript.

\section{Funding}

Financial support by the Austrian Science Foundation FWF (P26363-25; I 2984B25) is gratefully acknowledged.

\section{Availability of data and materials}

The transcriptome datasets generated and analyzed during the current study are available in the NCBI's Gene Expression Omnibus and are accessible through accession number GSE172092 (https://www.ncbi.nlm.nih.gov/geo/ query/acc.cgi?acc=GSE172092).

The proteome datasets generated and analyzed during the current study are available in the PRIDE Proteomics Identification Database and are accessible through accession number PXD025435 (https://www.ebi.ac.uk/pride/archive/ projects/PXD025435).

\section{Declarations}

Ethics approval

All experimental procedures were approved by the Tierversuchskommission of the University of Innsbruck, Austria. All methods were carried out in accordance with relevant guidelines and regulations. All methods are reported in accordance with ARRIVE guidelines (https://arriveguidelines.org).

Consent for publication

Not applicable. 


\section{Competing interests}

Authors declare no competing interests.

\section{Author details}

${ }^{1}$ Institute of Zoology, University of Innsbruck, Innsbruck, Austria. ${ }^{2}$ Center for Molecular Biosciences, University Innsbruck, Innsbruck, Austria. ${ }^{3}$ Future Genomics Technologies, Leiden, The Netherlands. ${ }^{4}$ Institute of Medical Biochemistry, Protein Core Facility, Medical University Innsbruck, Innsbruck, Austria. ${ }^{5}$ Institut für Zoologie Leopold-Franzens-Universität Innsbruck, Technikerstr. 25, A-6020 Innsbruck, Austria.

Received: 23 June 2021 Accepted: 16 November 2021

Published online: 02 December 2021

\section{References}

1. Pelster B. Using the swimbladder as a respiratory organ and/or a buoyancy structure-Benefits and consequences. J Exp Zool Part A Ecol Integr Physiol. 2021 Apr 8;335(9-10):831-42. Available from: https://onlinelibr ary.wiley.com/doi/https://doi.org/10.1002/jez.2460

2. Berenbrink M, Koldkjaer P, Kepp O, Cossins AR. Evolution of Oxygen Secretion in Fishes and the Emergence of a Complex Physiological System. Science,. 2005 Mar 18:307(5716):1752-7. Available from: http://www. sciencemag.org/cgi/content/abstract/307/5716/1752

3. Berenbrink M, Koldkaer P, Hannah Wright E, Kepp O, Jose da Silva A. Magnitude of the Root effect in red blood cells and haemoglobin solutions of fishes: a tribute to August Krogh. Acta Physiol. 2011;202(3):583-92. Available from: https://doi.org/10.1111/j.1748-1716.2010.02243.x

4. Root RW. The respiratory function of the blood of marine fishes. Biol Bull. 1931;61:427-56

5. Pelster B, Weber RE. The physiology of the Root effect. Adv Comp Environ Physiol. 1991;8:51-77.

6. Pelster B. The generation of hyperbaric oxygen tensions in fish. News PhysiolSci. 2001;16:287-91.

7. Kuhn W, Ramel A, Kuhn HJ, Marti E. The filling mechanism of the swimbladder. Generation of high gas pressures through hairpin countercurrent multiplication. Experientia. 1963;19:497-511.

8. Kuhn HJ, Moser P, Kuhn W. Haarnadelgegenstrom als Grundlage zur Erzeugung hoher Gasdrücke in der Schwimmblase von Tiefseefischen. Nachweis der Sekretion kleiner Mengen von Milchsäure am Scheitel der Haarnadel als Ursache des Einzeleffektes. Pflügers Arch. 1962;275:231-7.

9. Pelster B. Buoyancy at depth. In: Randall DJ, Farrel AP, editors. Deep-Sea Fish. San Diego, USA: Academic Press; 1997. p. 195-237. (Fish Physiology).

10. Stray-Pedersen S, Steen JB. The effect of $\mathrm{Ca}^{++}, \mathrm{Mg}^{++}$and $\mathrm{H}^{+}$on the capillary permeability of the rete mirabile of the eel, Anguilla vulgaris L. Acta Physiol Scand. 1975;94:423-41.

11. Rasio EA, Bendayan M, Goresky CA. Diffusion permeability of an isolated rete mirabile. Circ Res. 1977;41:791-8.

12. Wittenberg JB, Wittenberg BA. The choroid rete mirabile of the fish eye. I. Oxygen secretion and structure: Comparison with the swimbladder rete mirabile. Biol Bull. 1974;146:116-36.

13. Steen JB. The physiology of the swimbladder in the eel Anguilla vulgaris. III. The mechanism of gas secretion. Acta Physiol Scand. 1963;59:221-41.

14. Kobayashi H, Pelster B, Scheid P. Water and lactate movement in the swimbladder of the eel, Anguilla anguilla. Respir Physiol. 1989;78:45-57.

15. Halestrap AP. The monocarboxylate transporter family-Structure and functional characterization. IUBMB Life. 2012;64(1):1-9. Available from: http://doi.wiley.com/https://doi.org/10.1002/iub.573

16. Pelster B, Kobayashi $H$, Scheid P. Solubility of nitrogen and argon in eel whole blood and its relationship to pH. J Exp Biol. 1988;135:243-52.

17. Kobayashi H, Pelster B, Scheid P. Solute back-diffusion raises the gas concentrating efficiency in counter-current flow. Respir Physiol. 1989;78:59-71.

18. Fänge R. The mechanisms of gas transport in the euphysoclist swimbladder. Acta Physiol Scand Suppl. 1953;30(110):1-133. Available from: http:// www.ncbi.nlm.nih.gov/pubmed/14349731

19. Marshall NB. Swimbladder structure of deep-sea fishes in relation to their systematics and biology. DiscoverReports. 1960;31:1-122.

20. Fänge R. Gas exchange in fish swim bladder. Rev Physiol Pharmacol. 1983;97(C):111-58.
21. Kobayashi $\mathrm{H}$, Pelster $\mathrm{B}, \mathrm{Sch}$ eid $\mathrm{P} . \mathrm{CO}_{2}$ back-diffusion in the rete aids $\mathrm{O}_{2}$ secretion in the swimbladder of the eel. Respir Physiol. 1990 Mar;79(3):231-42.

22. Stray-Pedersen S, Nicolaysen A. Qualitative and quantitative studies of the capillary structure in the rete mirabile of the eel, Anguilla vulgaris L. Acta Physiol Scand. 1975;94:339-57.

23. Wagner RC, Froehlich R, Hossler FE, Andrews SB. Ultrastructure of capillaries in the red body (rete mirabile) of the eel swim bladder. Microvasc Res. 1987;34:349-62.

24. Righton D, Westerberg H, Feunteun E, Okland F, Gargan P, Amilhat E, et al. Empirical observations of the spawning migration of European eels: The long and dangerous road to the Sargasso Sea. Sci Adv. 2016;2(10):e1501694. Available from: http://www.ncbi.nlm.nih.gov/ pmc/articles/PMC5052013/

25. Aroua S, Schmitz M, Baloche S, Vidal B, Rousseau K, Dufour S. Endocrine Evidence that Silvering, a Secondary Metamorphosis in the Eel, Is a Pubertal Rather than a Metamorphic Event. Neuroendocrinology. 2005;82(34):221-32. Available from: https://www.karger.com/Article/FullText/92642

26. Rousseau K, Aroua S, Dufour S. Eel Secondary Metamorphosis. In: Dufour S, Rousseau K, Kapoor B, editors. Metamorphosis in Fish. CRC Press; 2012. p. 216-49. Available from: https://www.taylorfrancis.com/ books/9781439883310/chapters/https://doi.org/10.1201/b11774-8

27. Kleckner RC. Swim bladder volume maintenance related to migratory depth in silver phase Anguilla rostrata. Science,. 1980;208:1481-2.

28. Yamada Y, Zhang H, Okamura A, Tanaka S, Horie N, Mikawa N, et al. Morphological and histological changes in the swim bladder during maturation of the Japanese eel. J Fish Biol. 2001;58(3):804-14.

29. Aarestrup K, Okland F, Hansen MM, Righton D, Gargan P, Castonguay $M$, et al. Oceanic spawning migration of the European eel (Anguilla anguilla). Science (80-). 2009 Sep;325(5948):1660.

30. Schabetsberger R, Miller MMJM, Dall'Olmo G, Kaiser R, Økland F, Watanabe $\mathrm{S}$, et al. Hydrographic features of anguillid spawning areas: potential signposts for migrating eels. Mar Ecol Prog Ser. 2016 Jul 28;554(July):141-55. Available from: http://www.int-res.com/abstracts/meps/v554/p141-155/

31. Sébert $P$, Vettier $A$, Amerand A, Moisan C. High pressure resistance and adaptation of European eels. In: Van den Thillart G, Dufour S, Rankin JC, editors. Spawning Migration of the European Eel. New York: Springer Verlag; 2009. p. 99-127. (Fish and Fisheries).

32. Henkel CV, Burgerhout $E$, de Wijze DL, Dirks RP, Minegishi Y, Jansen HJ, et al. Primitive Duplicate Hox Clusters in the European Eel's Genome. PLoS One. 2012 Feb 24;7(2):e32231. Available from: http://dx.doi. org/10.1371\%2Fjournal.pone.0032231

33. Meyer A, Van de Peer Y. From $2 R$ to $3 R$ : evidence for a fish-specific genome duplication (FSGD). BioEssays. 2017;27:937-45.

34. Taylor JS, Van de Peer Y, Braasch I, Meyer A. Comparative Genomics Provides Evidence for an Ancient Genome Duplication Event in Fish. Philos Trans Biol Sci. 2001;356(1414):1661-79. Available from: http:// www.jstor.org/stable/3066685

35. Sialana FJ, Schneebauer G, Paunkov A, Pelster B, Lubec G. Proteomic Studies on the Swim Bladder of the European Eel (Anguilla anguilla). Proteomics. 2018(8):1700445. Available from: https://doi.org/doi.wiley. com/10.1002/pmic.201700445

36. Pelster B, Schneebauer G, Dirks RP. Anguillicola crassus infection significantly affects the silvering related modifications in steady state mRNA levels in gas gland tissue of the European eel. Front Physiol. 2016;7:175. Available from: http://www.frontiersin.org/Journal/Abstract.aspx?s= $54 \&$ name=aquatic physiology\&ART_DOI=10.3389/fphys. 2016.00175

37. Schneebauer G, Dirks RP, Pelster B. Anguillicola crassus infection affects mRNA expression levels in gas gland tissue of European yellow and silver eel. PLoS One. 2017;12(8):e0183128. Available from: https://doi. org/10.1371/journal.pone.0183128

38. Marguerat S, Schmidt A, Codlin S, Chen W, Aebersold R, Bähler J. Quantitative analysis of fission yeast transcriptomes and proteomes in proliferating and quiescent cells. Cell. 2012;151(3):671-83. Available from: http://www.ncbi.nlm.nih.gov/pubmed/23101633

39. Liu Y, Beyer A, Aebersold R. On the Dependency of Cellular Protein Levels on mRNA Abundance. Cell. 2016 Apr;165(3):535-50. Available from: https://linkinghub.elsevier.com/retrieve/pii/S0092867416302707

40. Franks A, Airoldi E, Slavov N. Post-transcriptional regulation across human tissues. Vogel C, editor. PLOS Comput Biol. 2017 8;13(5):e1005535. Available from: https://doi.org/dx.plos.org/10.1371/journal.pcbi.1005535 
41. Wang D, Eraslan B, Wieland T, Hallström B, Hopf T, Zolg DP, et al. A deep proteome and transcriptome abundance atlas of 29 healthy human tissues. Mol Syst Biol. 2019 Feb 18;15(2). Available from: https://onlinelibrary. wiley.com/doi/https://doi.org/10.15252/msb.20188503

42. Umezawa T, Kato A, Ogoshi M, Ookata K, Munakata K, Yamamoto Y, et al, $\mathrm{O}_{2}$-Filled Swimbladder Employs Monocarboxylate Transporters for the Generation of $\mathrm{O}_{2}$ by Lactate-Induced Root Effect Hemoglobin. Halsey LG, editor. PLoS One. 2012 Apr 4;7(4):e34579. Available from: https://doi.org/ dx.plos.org/10.1371/journal.pone.0034579

43. XuY, Fisher GJ. Receptor type protein tyrosine phosphatases (RPTPs) roles in signal transduction and human disease. J Cell Commun Signal. 2012;6(3):125-38. Available from: http://link.springer.com/https://doi.org/ 10.1007/s12079-012-0171-5

44. Pelster B, Scheid P. The influence of gas gland metabolism and blood flow on gas deposition into the swimbladder of the European eel Anguilla anguilla. J Exp Biol. 1992;173(1):205-16.

45. Rasio EA. Glucose metabolism in an isolated blood capillary preparation. Can J Biochem. 1973;51:701-8.

46. Rasio EA, Bendayan M, Goresky CA. Effect of temperature change on the permeability of eel rete capillaries. Circ Res. 1992;70:272-84.

47. Jasiński A, Kilarski W. Capillaries in the rete mirabile and in the gas gland of the swim bladder in fishes, Perca fluviatilis L. and Misgurnus fossilis L. An electron microscopic study. Acta Anat (Basel). 1971;78(2):210-23. Available from: http://www.ncbi.nlm.nih.gov/pubmed/5576211

48. Alexander RM. Physical aspects of swimbladder function. Biol Rev. 1966;41:141-76.

49. Jones FRH, Marshall NB. The structure and functions of the teleostean swimbladder. Biol Bull. 1953;28:16-83.

50. Fänge R. Physiology of the swimbladder. Bolis L, Schmidt-Nielsen K, Maddrell SHP, editors. Physiol Rev. 1966;46:299-322.

51. Morris SM, Albright JT. Catalase, glutathione peroxidase, and superoxide dismutase in the rete mirabile and gas gland epithelium of six species of marine fishes. J Exp Zool. 1984;232:29-39.

52. Schneebauer G, Hanel R, Pelster B. Anguillicola crassus impairs the silvering-related enhancements of the ROS defense capacity in swimbladder tissue of the European eel (Anguilla anguilla). J Comp Physiol B. 2016;186(7):867-77. Available from: https://doi.org/10.1007/ s00360-016-0994-0

53. Pelster B, Wood CM. lonoregulatory and oxidative stress issues associated with the evolution of air-breathing. Acta Histochem. 2018;120(7):667-79. Available from: https://linkinghub.elsevier.com/retrieve/pii/S006512811 830309X

54. Pelster B, Kobayashi $H$, Scheid P. Metabolism of the perfused swimbladder of European eel: oxygen, carbon dioxide, glucose and lactate balance. J Exp Biol. 1989;144:495-506.

55. Dirks RP, Burgerhout E, Brittijn SA, de Wijze DL, Ozupek H, Tuinhof-Koelma $\mathrm{N}$, et al. Identification of molecular markers in pectoral fin to predict artificial maturation of female European eels (Anguilla anguilla). Gen Comp Endocrinol. 2014;204(0):267-76. Available from: http://www.sciencedir ect.com/science/article/pii/S0016648014002561

56. Burgerhout E, Minegishi Y, Brittijn SA, de Wijze DL, Henkel C V, Jansen HJ et al. Changes in ovarian gene expression profiles and plasma hormone levels in maturing European eel (Anguilla anguilla); Biomarkers for broodstock selection. Gen Comp Endocrinol. 2016;225:185-96. Available from: http://www.sciencedirect.com/science/article/pii/S0016648015002117

57. Trapnell C, Pachter L, Salzberg SL. TopHat: discovering splice junctions with RNA-Seq. Bioinformatics. 2009 1;25(9):1105-11. Available from: http://bioinformatics.oxfordjournals.org/content/25/9/1105.abstract

58. Li H, Handsaker B, Wysoker A, Fennell T, Ruan J, Homer N, et al. The Sequence Alignment/Map format and SAMtools. Bioinformatics. 2009;25:2078-9. Available from: http://bioinformatics.oxfordjournals.org/ content/25/16/2078.abstract

59. Anders S, Pyl PT, Huber W. HTSeq - a Python framework to work with high-throughput sequencing data. Bioinformatics. 2015;31:166-9.

60. Anders S, Huber W. Differential expression analysis for sequence count data. Genome Biol. 2010;11:R106.

61. Fabregat A, Jupe S, Matthews L, Sidiropoulos K, Gillespie M, Garapati P, et al. The Reactome Pathway Knowledgebase. Nucleic Acids Res. 2018;46(D1):D649-55. Available from: http://www.ncbi.nlm.nih.gov/ pubmed/29145629
62. Wiśniewski JR, Zougman A, Nagaraj N, Mann M. Universal sample preparation method for proteome analysis. Nat Methods. 2009 19;6(5):359-62. Available from: http://www.nature.com/articles/nmeth.1322

63. Lamberti G, De Smet CH, Angelova M, Kremser L, Taub N, Herrmann C, et al. LAMTOR/Ragulator regulates lipid metabolism in macrophages and foam cell differentiation. FEBS Lett. 2020;594(1):31-42. Available from: https://onlinelibrary.wiley.com/doi/abs/https://doi.org/10.1002/18733468.13579

64. Durif CMF, Dufour S, Elie P. The silvering process of Anguilla anguilla: a new classification from the yellow resident to the silver migrating stage. J Fish Biol. 2005;66(4):1025-43.

65. Pankhurst NW. Relation of visual changes to the onset of sexual maturation in the European eel Anguilla anguilla (L.). J Fish Biol. 1982;21(2):127-40.

\section{Publisher's Note}

Springer Nature remains neutral with regard to jurisdictional claims in published maps and institutional affiliations.
Ready to submit your research? Choose BMC and benefit from:

- fast, convenient online submission

- thorough peer review by experienced researchers in your field

- rapid publication on acceptance

- support for research data, including large and complex data types

- gold Open Access which fosters wider collaboration and increased citations

- maximum visibility for your research: over $100 \mathrm{M}$ website views per year

At BMC, research is always in progress.

Learn more biomedcentral.com/submissions 